\begin{tabular}{|c|c|c|}
\hline 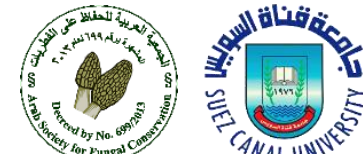 & $\begin{array}{c}\text { Contents lists available at Egyptian Knowledge Bank } \\
\text { Microbial Biosystems } \\
\text { Journal homepage: http://mb.journals.ekb.eg/ }\end{array}$ & $\begin{array}{l}\text { MICROBIAL BIOSYSTEMS } \\
\text { INTERNATIONAL SGIENTIFIC JOURNAL } \\
\text { OF MICROBIAL BIOLOGY }\end{array}$ \\
\hline
\end{tabular}

\title{
The role of endophytic fungi in combating abiotic stress on tomato
}

\author{
Fatma A. Abo Nouh*, Abdelghafar M. Abu-Elsaoud, Ahmed M. Abdel-Azeem
}

Botany and Microbiology Department, Faculty of Science, Suez Canal University, Ismailia 41522, Egypt.

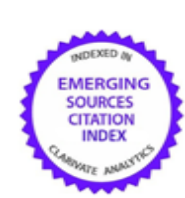

\author{
ARTICLE INFO

\section{Article history} \\ Serag M. S. \\ Amrani $\mathrm{S}$.

\section{Keywords} \\ Endophytic fungi \\ abiotic stress \\ drought \\ salinity \\ STDF
}

Received 20 August 2021

Received revised 29 August 2021

Accepted 30 August 2021

Available online 31 August 2021

(C) Abo Nouh et al., 2021

Corresponding Editor:

\begin{abstract}
Environmental stress to plants is more detrimental than biotic stress. Abiotic stresses, such as drought, salinity, extreme temperatures, heavy metal toxicity, and oxidative stress, are serious threats to agriculture and lead to deterioration of the environment. Abiotic stress leads to a series of morphological, physiological, biochemical, and molecular changes that have a harmful effect on plant growth and productivity. Recently endophytic fungi (EF) are gaining attention due to the numerous benefits gained by the host plant and reducing the application of chemicals in agriculture, thus providing advantages to human health and the environment. Indeed, microbe's ability to confer plant stress resistance may open a new avenue for alleviating the adverse effect of global climate change on agricultural production. The ability of endophytes recovered from grasses were applied to confer drought, high temperature and high salinity to genetically distant plants such as tomato. The concept that fungal endophytes adapt to stress in a habitat-specific manner has been confirmed with different fungal and plant species and environmental stresses. In this review, we have tried to comprehend different roles of endophytes in combating abiotic stress on tomato.
\end{abstract}

Published by Arab Society for Fungal Conservation

\section{Introduction}

The beginning of $21^{\text {st }}$ century is marked by global scarcity of water resources, environmental pollution, and increased salinization of soil and water. Increasing human population and reduction in land available for cultivation are two threats for agricultural sustainability (Shahbaz and Ashraf 2013).

Light, water, carbon, and mineral nutrients are the major requisites of plants for growth, development, and reproduction. Being immobile, plants are exposed to various environmental stresses and stresses induced by living entities that they cannot escape (Lata et al., 2018).

Agriculture is considered to be one of the most vulnerable sectors to climate change. Crop production, particularly in tropical regions, is facing increasing stresses caused due to natural and anthropogenic factors. Generally, the stress in plants refers to external conditions that adversely affect plants' growth, development, or productivity (Verma et al., 2013).

Stresses trigger a wide range of plant responses, e.g., cellular metabolism, altered gene expression, changes in growth rates, crop yields, etc. (Kour et al. 2019). Plant stress usually reflects some changes in environmental conditions. Plant stress has two categories: abiotic stress and biotic stress (Yadav et al., 2017).

Abiotic stress affects plants by the environment may be physical or chemical, while biotic stress exposed to the crop plants is a biological unit like diseases, insects, etc. Generally, plants in natural systems and croplands are simultaneously exposed to both biotic and abiotic stresses (Verma et al. 2013). Abiotic stresses such as drought (water stress), extreme temperatures (cold, frost, and heat), salinity,

\footnotetext{
* Corresponding author

E-mail address: fatma.nouh@science.suez.edu.eg (Fatma Ahmed Abo Nouh)
} 
excessive watering (waterlogging), and mineral toxicity negatively impact the growth, development, yield, and seed quality of crops and other plants. Abiotic stress tolerance plays an indispensable role in determining crop productivity and distribution of plant species across the environment (Chaves et al., 2003). These factors are cause a serious negative impact on crop growth and yields and force severe pressure on land and water resources (Grover et al. 2011).

Environmental stresses such as drought, temperatures, salinity, or toxicity bring serious consequences to crop production, causing collectively more than $50 \%$ yield losses worldwide (Wang and Frei 2011). Due to global climate change, abiotic stresses are expected to become more widespread in the coming decades and pose serious global food security threats (Abo Nouh and Abdel-Azeem 2020).

Tomato (Solanum lycopersicum L.) is the second most important vegetable crop next to potato globally. The fruits of vegetable crops have incredible nutritional value as an important origin of vitamins (A and $\mathrm{C}$ ), minerals, and lycopene (antioxidants) that provide the human body with a healthy regime (Niu et al. 2013). Tomato is one of the most important horticultural crops farmed due to its extensive global distribution and consumption, but unfortunately, Desneux et al. (2011) reported due to climate favorability for expansion and damaging potential of Tomato Leaf Miner (TLM), world tomato production has drastically reduced since 2006. Tomato production has been confounding by many biotic and abiotic constraints. Abiotic stresses are virtually interrelated; either individually or in combination, they cause morphological, physiological, biochemical, and molecular changes that negatively affect plant growth, productivity, and ultimately yield.

Practical strategies were developed worldwide for mitigating stress toxic effects through the development of tolerant varieties, shifting crop calendars, using chemicals that may be toxic for the environment, resource management practices, etc. (Grover et al. 2011). But most of these practices are time-consuming and costly. While microbial inoculation is safe, low-cost, effective, the environmentfriendly approach can increase plant stress tolerance and maintain ecosystem health (Naveed et al. 2014; Meena et al. 2015).

Indeed, microbe's ability to confer plant stress resistance may open a new avenue for alleviating the adverse effect of global climate change on agricultural production (Grover et al., 2011). It can enhance crop production and protection by promoting seed germination; enhancing plant growth, root development, fruiting, flowering, and ripening; increasing the efficacy of organic matter as fertilizers; developing resistance of plants to pests and diseases; increasing nutrient availability in the rhizosphere of plants; suppressing soil-borne pathogens and pests; and increasing the production of antioxidants that suppress the negative impact of free radicals in plant metabolism (Higa 2004; Talaat 2015). It can also decrease the damage to plants caused by soil salinization by improving various physiological and biochemical processes inside the plant cell (Talaat 2014).

\section{Tomato (Solanum lycopersicum L.)}

Tomato (S. lycopersicum L.) is an eudicotiledonous plant that belongs to the family Solanaceae and other economically important crops such as pepper, eggplant and potato. The high level of consumption of tomato makes it one of the main sources of minerals and vitamins (Khan et al. 2014). Tomatoes contain various phytochemicals such as $\beta$ carotene, lycopene, flavonoids, vitamins $\mathrm{A}$ and $\mathrm{C}$, and many other essential nutrients and have been found valuable to human health (Beutner et al. 2001).

According to Desneux et al. (2011), Tomato is the most important grown fresh market vegetable worldwide with more than 5 million hectares harvested in China, United States of America, India, Turkey, and Egypt as the five first producers. But due to climate favorability for expansion and the damaging potential of Tomato, world tomato production has drastically reduced since 2006 , and tomato production in Egypt. World harvested area increased from 4.5 million hectare in 2010 to 5.02 million hectares in 2014 , this showed area covered by tomato increased by $10.4 \%$; yield from harvested areas were 151.9 million KT (kilotonne) in 2010 and1.71 billion KT in 2014 with yield per hectare 34 MT (metric tonne) in 2014. In Africa, yield decreased from 18.6 million MT in 2010 to 15.9 million MT in 2014, reducing by 14.6. While, in eastern Africa Yield (hg/ha) decreased from 131488 in 2010 to 128239 in 2014 which showed total yield decreased by $2.5 \%$ (FAOSTAT 2014). As this report showed, world tomato production per unit area is decreasing.

Production of tomato in temperate regions is usually done under greenhouse conditions in hydroponic plant cultivation systems (Schwarz et al. 1996). Tomato production has been confounding by many biotic and abiotic constraints. Abiotic stresses are virtually interrelated; either individually or in combination, they cause morphological, physiological, biochemical, and molecular changes that negatively affect plant growth, productivity, and ultimately yield (Savvas et al. 2003).

\section{Abiotic Stress Effect on Agriculture Crops}

Due to significant climatic changes, a global water shortage is the leading cause of these abiotic stresses, including drought, extreme temperatures, and salinity (Redman et al. 2011). Abiotic stress is the primary cause of crop loss worldwide, reducing average yields for most major crop plants by more than 50\% of crop yield (Boyer 1982). Plant responses to abiotic stresses are dynamic and complex 
(Skirycz and Inze 2010); they are both elastic (reversible) and plastic (irreversible). The plant responses to stress are dependent on the tissue or organ affected by the stress (Cramer et al. 2011). Abiotic stress leads to a series of morphological, physiological, biochemical, and molecular changes that adversely affect plant growth and productivity (Wang et al. 2001; Yadav 2017).

Abiotic stresses, such as drought, salinity, extreme temperatures, and heavy metal toxicity are serious threats to agriculture and result in the damage of the environment (Singh et al. 2011; Saxena et al. 2016; Yadav 2019). Drought, salinity, and extreme temperatures, often interconnected, result in oxidative burst and cellular damage (Kaur et al. 2020; Rana et al. 2020). E.g., water stress and salinization, which are apparent osmotic stress, disrupt the ion distribution and metabolism in the cell (Raghuwanshi 2018). Among abiotic stresses, drought stress, soil salinity, and accumulation of heavy metals (HM) in the soil are among the major grounds of diminished plant performance and restrained crop yield worldwide (López-Ráez 2016). In response to these damage, plants modify their root morphology, ultrastructure (Fusconi and Berta 2012), which may modulate their physiology and biochemistry to limit stress-induced damages and/or facilitate the repair of damaged systems (Latef et al. 2016).

\section{Salinity}

Salinity is the presence of excessive amounts of soluble salts that affect plant growth's normal functions. Soil salinization is a devastating ecological and agronomical problem that limits agricultural production and land development in many areas on the earth. Approximately $7 \%$ of the global land surface is salt-affected. More than 45 million hectares of irrigated land have been damaged by salt, and 1.5 million hectares are taken out of production each year as a result of high salinity levels in the soil in the world (Munns and Tester 2008). Soil salinity is a huge problem for agriculture under irrigation and affecting crop performance, as it inhibits seed germination and seedling growth and leads to yield reduction (Cuartero et al. 2006).

In hot regions of the world the soils are almost saline with low agricultural ability. In these areas most crops are grown under irrigation, and to get worth the problem, inadequate irrigation management leads to secondary salinization that affects $20 \%$ of irrigated land worldwide (Glick et al. 2007). Irrigated agriculture is a major human activity, which often leads to secondary salinization of land and water resources in arid and semi-arid conditions.

Salts in the soil occur as ions (electrically charged forms of atoms or compounds). Ions are released from weathering minerals in the soil. When precipitation is insufficient to leach ions from the soil profile, salts accumulate, resulting in soil salinity (Blaylock et al. 1994). Plants absorb essential nutrients in soluble salts, but excessive accumulation strongly suppresses the plant growth. A saline soil is generally defined as one in which the electrical conductivity (EC) of the saturation extract (ECe) in the root zone exceeds $4 \mathrm{dS} \mathrm{m} 1$ (approximately $40 \mathrm{mM} \mathrm{NaCl}$ ) at $25{ }^{\circ} \mathrm{C}$ and has an exchangeable sodium of $15 \%$. The yield of most crop plants is reduced at this ECe, though many crops exhibit yield reduction at lower ECes (Munns 2005; Jamil et al. 2011). It has been estimated that worldwide $20 \%$ of total cultivated and $33 \%$ of irrigated agricultural lands are afflicted by high salinity.

Furthermore, the salinized areas are increasing at a rate of $10 \%$ annually for various reasons, including low precipitation, high surface evaporation, weathering of native rocks, irrigation with saline water, and poor cultural practices. Water and soil management practices have facilitated agricultural production on soil marginalized by salinity, but these approaches' additional gain seems problematic (Zahir et al. 2008). Some scientists predict that at 2050 , more than $50 \%$ of the agricultural land will be salinized (Jamil et al. 2011).

\section{Impact of salinity on plants}

Agricultural crops exhibit a range of responses under salt stress. Plant cells can sense salt stress through membrane disorganization; metabolic toxicity; enzyme damage; inhibition of photosynthesis, respiration, and protein synthesis; disturbance in water and osmotic potential; reduction in assimilate translocation to sinks; disturbance in nutrient accumulation; toxicity of excessive $\mathrm{Na}^{+}$and $\mathrm{Cl}^{-}$; and increasing ROS production in chloroplasts (Talaat and Shawky 2013). Salinity effects on plant development e.g. germination, vegetative growth and reproductive development. Soil salinity imposes ion toxicity, osmotic stress, nutrient (N, K, P, Ca, Fe, Zn) deficiency and oxidative stress on plants, and thus limits water uptake from soil. Soil salinity reduces plant phosphorus uptake because phosphate ions precipitate with Ca ions (Bano and Fatima 2009).

During the onset and development of salt stress within a plant, major processes such as photosynthesis, protein synthesis, and energy and lipid metabolism are affected (Carillo et al. 2011; Singh et al. 2020). About 45 million hectares of irrigated land is affected by salt worldwide (Munns and Tester 2008). Generally, salt stress affects plants in numerous ways such as ion toxicity, oxidative stress, nutritional disorders, physiological drought, modification of metabolic processes, membrane incompetence, and reduction of cell division (Zhu 2007).

At low salt concentrations, yields are mildly affected or not affected at all (Maggio et al. 2001). When a plant is exposed to high salt at germination it causes physiological 
drought and reduction in leaf expansion. The osmotic effects of salinity stress can be observed immediately after salt application and are believed to continue for the duration of exposure, resulting in inhibited cell expansion, cell division, and stomatal closure (Munns 2002). If plants are exposed for long time to salinity, plants face ionic stress, which can direct to premature senescence of adult leaves, and thus a reduction in the photosynthetic area available to support continued growth (Cramer and Nowak 1992). High salt concentration in soil affects plants in two ways; at first high concentrations of salts in the soil upset the ability of roots to extract water, and secondly high concentrations of salts within the plant itself can be toxic, resulting in an inhibition of many physiological and biochemical processes e.g. nutrient uptake and assimilation (Batool et al. 2014). A plant's first line of defense against abiotic stress is in its roots.

\section{Drought}

Drought is one of the most environmental factors that limit crop production by altering a series of physiological, biochemical, and molecular responses. It disrupts photosynthesis and protein synthesis, increases photorespiration, alters the normal homeostasis of cells, affects plant hormone balance, and induces high levels of ROS in plant cells (Cohen et al. 2015).

Among the environmental stresses, drought, which is commonly known as water stress, is considered one of the major challenges to crop production worldwide (Yue et al. 2006). Drought is the most significant abiotic stress, adversely affecting the productivity and distribution of crop plants worldwide about $45 \%$ of the global agricultural land (Hussain et al. 2018). The agriculture sector is highly vulnerable to drought, as it depends directly on water availability (Liu and Hwang 2015; Meng et al. 2016; Parker et al. 2019). An agricultural drought is characterized by a period with dry soils due to lack of precipitation, intense but less frequent rain events, gaps between factual and projected evapotranspiration, water deficits in soil, decreased groundwater or reservoir level all of which lead to reduced plant growth and crop production (Mannocchi et al. 2004; Dalezios et al. 2017). Severe droughts have caused substantial decline in crop yields through negative impacts on plant growth, physiology, and reproduction.

A metanalysis of the data from 1980 to 2015 reported a global yield reduction up to 21 and $40 \%$ in wheat and maize crop, respectively due to drought (Daryanto et al. 2016). Drought stress is among the most destructive abiotic stresses that increased in intensity over the past decades affecting world's food security. Drought stress may range from moderate and short to extremely severe and prolonged, restricting the crop yields (Bottner et al.1995). Drought is expected to cause serious plant growth problems for more than $50 \%$ of the arable lands by 2050 (Kasim et al. 2013).

\section{Impact of drought on plants}

Agricultural drought known as extended dry period that results in crop stress and crop yield disorder. It causes the dehydration of cells and osmotic imbalance (Mahajan and Tuteja 2005). Severe droughts occur periodically in several major food-producing countries, severely impacting global food production and supply. Drought affects plant-water potential and turgor, enough to interfere with normal functions; (Hsiao 2000) changing physiological and morphological traits in plants (Rahdari and Hoseini 2012). Fresh weight and water content are common growth parameters affected by drought (Jaleel et al. 2009).

Furthermore, drought stress influences the availability and transport of soil nutrients, as nutrients are carried to the roots by water. Drought stress there-fore decreases nutrient diffusion and mass flow of water-soluble nutrients such as nitrate, sulfate, $\mathrm{Ca}, \mathrm{Mg}$, and $\mathrm{Si}$ (Selvakumar et al. 2012). Drought also induces free radicals affecting antioxidant defenses and Reactive Oxygen Species (ROS) such as superoxide radicals, hydrogen peroxide and hydroxyl radicals resulting in oxidative stress (Smirnoff 1993), like initiate lipid peroxidation, membrane deterioration and degrade proteins, lipids and nucleic acids in plants (Hendry 2005).

Nevertheless, under drought stress the decrease in chlorophyll content was symptom of photooxidation (Anjum et al. 2011). Drought also affects biochemical activities like nitrate reductase (NR), due to lower uptake of nitrate from the soil (Caravaca et al. 2005). It also accentuates the biosynthesis of ethylene, which inhibits plant growth through several mechanisms (Ali et al. 2014). Drought as a multidimensional stress, affects at various sub cellular compartment, cell organs and whole plant level (Rahdari et al. 2012). Thus, drought negatively affects quantity and quality of growth in plants. Therefore, to produce more food, the mitigation of drought stresses is important to achieve the designated goals.

Worldwide extensive research is being carried out to develop strategies to cope with drought stress by developing drought tolerant varieties, shifting the crop calendars, resource management practices, etc (Venkateswarlu and Shanker 2009). Most of these technologies are costintensive.

\section{Fungal endophytes}

Fungal symbionts associated with plants are classified to two major classes: (1) Endophytic fungi, which reside entirely within plant tissues and may be associated with roots, stems, or leaves; and (2) Mycorrhizal fungi that reside only in roots but extend out into the rhizosphere (Singh et al. 2011; Rana et al. 2019). Evidence of plant-associated microorganisms found in the fossilized tissues of stems and leaves has 
revealed that endophytic-plant associations may have evolved more than 400 million years ago (Kusari and Spiteller 2012). Studies of endophytic fungi were initiated nearly 200 years ago, when in 1772 the species Sphaeria typhina described, now known as Epichloe typhina (Khiralla et al. 2016). After more than 100 years of research it is reasonable to conclude that most, if not all, multicellular life on earth is symbiotic with microorganisms.

Endophytes are ubiquitous in the plant world; no report of a plant species not associated with them is known; individuals without endophytes are rare in a given plant species (Zabalgogeazcoa 2008). Unlike mycorrhizal fungi, fungal endophytes are microfungi that internally infect living plant tissues without causing disease or any harm to plant, and live in mutualistic association with plants for at least a part of their life cycle (Kusari and Spiteller 2012; Lugtenberg et al. 2016; Arora and Ramawat 2017; Khare et al. 2018; Chhipa and Deshmukh 2019; Abo Nouh 2019). Based on the survey conducted in the last 20 years on endophytes, it is thought that the majority, if not all plants, have one or more types of these endophytes and numerous endophytic species; in some cases, above a hundred can be found in a certain plant species (Arnold 2007).

\section{Fungal Symbiosis and Habitat-adapted Symbiosis}

Symbiosis, known as the permanent association between two or more specifically distinct organisms, at least during a part of the life cycle, this association is ubiquitous and important aspect of life on Earth (Kour et al. 2019). Symbiotic fungi have two functional groups (endophytic and mycorrhizal fungi) based on plant colonization patterns, transmission, and ecological functions (Brundrett 2006). The outcome of plantfungal symbiotic interactions is defined by the fitness benefits realized by each partner (Lewis and Clements 1986). Host fitness benefits can be positive (mutualism), neutral (commensalism and neutralism), or negative (parasitism, competition, and amensalism) depending on the lifestyle expressed by the fungal endophyte (Rodriguez et al. 2008). Commensal symbioses have no beneficial or harmful effects on hosts, but parasitic symbioses negatively affect host fitness by decreasing growth rates or inducing disease symptoms that lead to death (Redman et al. 2001).

Successful plant-fungal symbioses contain three events: firstly, penetration by the fungus into plant tissues; secondly, colonization of plant tissues by the invading fungus; finally, expression of a fungal symbiotic lifestyle (Pieterse and Dicke 2007). It is assumed that some form of biochemical or genetic communication occurs between the symbionts and hosts that allow mutualists to confer physiological benefits to hosts (Singh et al. 2011). The communication that dictates the outcome of symbiotic associations remains an enigma but subtle differences in communication can alter the symbiotic lifestyle expressed (Schulz 2006). For example, fungal species within a genus and different isolates have been shown to express different symbiotic lifestyles ranging from mutualism to parasitism. This variation in lifestyle expression within a genus or species may occur due to host physiology (Graham et al. 1996; Graham and Eissenstat 1998); and is known as the Symbiotic Continuum (Schardl and Leuchtmann 2005; Schulz and Boyle 2005).

Variation in lifestyle expression was most dramatically demonstrated by a host range study of pathogenic Colletotrichum species (Redman et al. 2001). Individual Colletotrichum isolates could express either pathogenic or nonpathogenic symbiotic lifestyles depending on the host genotype they colonized. So that several isolates expressed mutualistic lifestyles conferring fitness benefits to plants such as disease resistance, growth enhancement, and drought tolerance. For example, $C$. protuberata isolates from panic grass (isolate $\mathrm{Cp} 4666 \mathrm{D}$ ) conferred heat tolerance to tomato, watermelon, and panic grass seedlings but, $C$. protuberata isolates from the non-thermal adapted grass Deschampsia flexuosa (isolate $\mathrm{CpMH206)} \mathrm{did} \mathrm{not} \mathrm{confer}$ heat tolerance to any plant (Rodriguez et al. 2008).

Moreover, the symbiotic communication responsible for heat tolerance in a monocot host (panic grass) appears to be the same in at least some eudicot hosts (tomato and watermelon). The lack of thermotolerance provided by CpMH206 suggests that symbiotically conferred thermotolerance results from habitat-specific adaptation by Cp4666D (Rodriguez et al. 2008). Other example, $C$. gloeosporioides was designated a pathogen of strawberry and a commensal of tomato because it conferred no disease protection (Redman et al. 2001); Nevertheless, $C$. gloeosporioides increased plant biomass and conferred drought tolerance to tomato plants and considered as a mutualist (Rodriguez and Redman 2008). Therefore, stress tolerance is not a direct result of fungal biomass, but must involve specific communication between stress-adapted endophytes and plant hosts. This suggests that symbiotically conferred stress tolerance's genetic and biochemical bases are conserved and evolved before the divergence of monocots and eudicots (Yang et al. 1999).

Symbiotic fungi are responsible for the adaptation of plants to environmental stresses (Khan et al. 2012), and these tolerances can be transferred to agricultural plants (Rodriguez et al. 2008; Redman et al. 2011); these endophytes can improve agriculture to combat climate changes, which involve increasing tolerance to drought and water stress and tolerance to high temperature and high salinity (Lugtenberg et al. 2016). The ability of endophytes recovered from grasses were applied to confer drought, high temperature and high salinity to genetically distant plants such as tomato (Chaw et al. 2004). The concept that fungal 
endophytes adapt to stress in a habitat-specific manner has been confirmed with different fungal and plant species and environmental stresses (Redman et al. 2002). This habitatspecific adaptation is defined as HA-symbiosis, and it is hypothesized that this allows plants to establish and survive in high-stress habitats (Rodriguez and Redman 2008).

\section{Plant growth-promoting endophytes (PGPE)}

Fungal endophytes have been gaining increased attention because of the numerous benefits they can offer directly or indirectly to the plant host with the intimate interaction established during the colonization of the plant tissues (Young et al. 2013). Since endophytes discovery, they have been isolated from different vegetative structures, many diverse plant species, both in natural uncultivated and in agricultural environments (Hyde and Soytong 2008). These EF represent a microbial community with an enormous biodiversity reserve, originating from diverse ecological niches and host tissues ranging from the algae living in marine environments (Parthasarathy et al. 2020), to trees in the forest ecosystems (Jia et al. 2020).

The beneficial effects executed by EF include plant growth promotion (PGP), improvement of the plant nutrient availability and uptake, pest and pathogen control, and the increased tolerance to abiotic stress, hereby referred to as plant physiology improvement (PPI) (Sánchez-Rodríguez et al. 2018). According to the reported literature, most true fungi characterized as PGPF primarily belong to the phylum Ascomycota (Aspergillus, Aureobasidium, Chaetomium, Cladosporium Colletotrichum, Exophiala, Penicillium, Trichoderma, Fusarium, Gliocladium, Phoma, Phomopsis, Purpureocillium, Talaromyces). A few belong to Basidiomycota (Limonomyces, Rhodotorula, Rhizoctonia) and Zygomycota (Mucor, Rhizopus). On average $44 \%$ of the rhizosphere fungal isolates were PGPF (Hyakumachi 1994).

Some fungi that live inside root tissues or endophytes also have diverse positive effects on plant growth and are PGPF (Waqas et al. 2015). The most dominant endophyte appears to be Fusarium (25\%), followed by Penicillium (12.5\%) and Alternaria (7.5\%) (Khalmuratova et al. 2015). Subsequent studies have also demonstrated the potential of phyllosphere fungi as PGPF (Limtong and Koowadjanakul 2012).

Plant growth-promoting endophytes (PGPE) inhabit plant tissues and the close linkage of endophytes inside plant tissues facilitates nutrients exchange and enzyme activity (Hassan 2017), and promote hormones production in plant tissue (Lin and $\mathrm{Xu}$ 2013). These endophytes possess a significant ability to mobilize insoluble phosphate and provide nitrogen to their host plants (Matsuoka et al. 2013). Plant growth promoting endophytes (PGPE) directly or indirectly produce several bioactive compounds with numerous biological activities, which considered as plant growth-promoting (PGP) agents and protectors (Lin and Xu 2013). Many studies have indicated that there was evident PGP as demonstrated by the improvement of the root system with greater root length, biomass, and dry weight (Tucci et al. 2011; Nefzi et al. 2019), increased plant height, shoot biomass, and fresh or dry weight (Vergara et al. 2017; Nefzi et al. 2019), plus enhanced plant production with anticipated flowering and fruiting times, and increased fruit weight (Zavala-Gonzalez et al. 2015). Moreover, a few articles reported improved plant nutrient uptake and the increased tolerance to abiotic stress (Table 1). Additionally, some studies have highlighted that the presence of the endophyte confers tolerance to diverse abiotic stress such as drought (Valli and Muthukumar 2018), salinity (Khan et al. 2013), and metals (Khan et al. 2015).

Impact of the PGPF on tomato growth and abiotic stress tolerance

The beneficial effects of microorganisms on plant development have been reported for numerous crops, including tomato grown either under field (Babu et al. 2015) or greenhouse conditions in organic media (Anupama et al. 2014). One of these beneficial microorganisms is plantgrowth-promoting fungi (PGPF), which enhances plant growth through various mechanisms (Jogaiah et al. 2018).

To date, in tomato the artificial introduction of EF has been limited to a restricted group of beneficial microbes which include species belonging to the genera Sarocladium, Beauveria, Metarhizium, Fusarium, Penicillium, Pochonia, Serendipita, Pythium, and Trichoderma (Akello et al. 2012; Akutse et al. 2013): and also some introduced species belong to the Dark Septate Endophytes (DSE) such as Neocosmospora haematococca and Periconia spp. DSE are ubiquitous and abundant in various ecosystems and playing an interesting role in contrasting pathogens as they can improve plant tolerance to abiotic stress (Valli and Muthukumar 2018), growth (Vergara et al. 2017), and nutrient uptake (Yakti et al. 2018).

Seeds germination and early stage of plant development effectually get benefit from PGPF; e.g. vigorous early seedling up growth was recorded in tomato seed inoculated with Phoma multirostrata, Penicillium chrysogenum (Murali et al. 2013) and Trichoderma harzianum (Jogaiah et al. 2013). According to Mushtaq et al. (2012), tomato seeds, which presoaked in the nine Penicillium isolates culture, showed significantly increasing germination compared with the control seeds. Inoculation of tomato plant with A. flavus isolated from the medicinal plant, Euphorbia geniculata enhanced the fresh weight, length, and production of tomato plants' lateral roots and root hairs. PGPF on tomato plants induced resistance to the pathogen 
Alternaria phragmospora and exhibited a healthy plant with high nutrients content.

Some endophytic fungi were shown to protect tomato crops from fungal infections (Hallman and Sikora 1995). Endophytic Fusarium oxysporum strain Fo47, applied as root treatment, had significantly controlled Fusarium wilt of tomato caused by $F$. oxysporum f. sp. lycopersici (Aimé et al. 2013). Moreover, Qian et al. (2017) noted 20\% decrease in Verticillium wilt on tomato plants colonized by Piriformospora indica. Rodriguez et al. (2006) showed that $F$. oxysporum to inhibit Sclerotinia sclerotiorum growth in infected tomato plants through the release of the antifungal metabolite cyclosporine.

Other fungal endophytes such as Fusarium fujikuroi, Sphaceloma manihoticola Cladosporium sp., Penicillium sp., and Aspergillus fumigatus enhanced tomato growth by releasing hormones (Schulz et al. 2002; Khan et al. 2012). Some previous studies demonstrated that wild Solanaceae plants are valuable sources of isolation of beneficial bioagents and extraction of bioactive compounds (Nefzi et al. 2017). Nigrospora sphaerica significantly increased shoot fresh weight by 13 and $22 \%$ over Curvularia lunata and the control, respectively. Concerning the nutritional status of tomato plants, both endophytes led to significant increase in nitrogen concentration in shoots when applying $50 \%$ of the recommended mineral fertilizer. $N$. sphaerica enhanced phosphorus concentration in shoots by $13 \%$ over the control (Saad and Badry 2020).

Symbiotically conferred abiotic stress tolerance involves at least two mechanisms: (1) activation of host stress response systems soon after exposure to stress, allowing the plants to avoid or mitigate the impacts of the stress (Redman et al. 1999) and (2) biosynthesis of antistress biochemicals by endophytes (Schulz et al. 2002). Fungal endophytes Chaetomium globosum and Penicillium resedanum isolated from Capsicum annuum plants promoted shoot length and biomass of the host plants subjected to drought stress (Khan et al. 2012). Drought-tolerance tomato plants showed higher root and shoot biomass when inoculated with class 2 fungal endophytes, including Alternaria sp. and T. harzianum (Azad and Kaminskyj 2016). Epichloë species may enhance the eco-physiology of host plants and enable plants to counter abiotic stresses such as drought and metal contamination (Rodriguez et al. 2009).

Grass species growing on coastal areas harbor symbiotic fungal endophytes, strengthening them against salinity and heat (Rodriguez et al. 2008). These endophytes have been reported to induce salt tolerance in several noncoastal plants. Leymus mollis (dune grass), plants harboring endophyte Fusarium culmorum, flourished on the coastal beaches of the USA, which are areas of high salinization. Salt-sensitive plants not growing in coastal areas could develop salt tolerance when inoculated with the endophyte F. culmorum (Rodriguez et al. 2008). Colletotrichum magna and Curvularia protuberata are well reported for water stress tolerance in wheat (Triticum sp.), tomato (Solanum lycopersicum), and watermelon (Citrullus lanatus) plants (Raghuwanshi 2018).

Fungal endophytes can provide fitness benefit to plants when exposed to water-limiting conditions. Perhaps the most widely documented example of endophytemediated drought stress tolerance in plants is the enhanced drought tolerance of tall fescue and perennial ryegrass due to infection of the endophyte Neotyphodium coenophialum (Dastogeer and Wylie 2017). But, all fungal endophytes can confer drought tolerance to plants regardless of the habitat of origin (Rodriguez et al. 2008). C. protuberata (Cp4666D) and $F$. culmorum (FcRed1) isolates from geothermal soil and Costal Beach both conferred similar levels of drought tolerance in tomato (Rodriguez et al. 2008). Trichoderma sp. produced different secondary metabolites; these compounds are reported as a plant defense activator in canola, pea, and tomato (Chhipa and Deshmukh 2019).

Treatment of seed with $T$. harzianum ameliorates a wide variety of biotic, abiotic, and physiological stresses to seed and seedlings. Trichoderma pseudokoningii isolated from tomato roots from central Himalaya exhibited PGP phosphate solubilization and synthesis of auxins, siderophores, HCN, and ammonia (Chadha et al. 2015). $F$. pallidoroseum has a significant positive role in plant growth and development. Inoculation of tomato seeds with $F$. pallidoroseum enhanced proline content; acid and alkaline phosphomonoesterase activity; and peroxidase activity (Srivastava et al. 2011).

Mutualistic benefits conferred by Colletotrichum spp. include growth enhancement, disease resistance, and/or drought tolerance (Redman et al. 2001). C. gloeosporioides increased plant biomass and conferred drought tolerance to tomato plants (Redman et al. 2002). One plant species (Dichanthelium lanuginosum) has been studied and found to be colonized by one dominant endophyte (Curvularia protuberata). C. protuberata confers heat and drought tolerance to the host plant. Curvularia spp. also confer heat and drought stress to tomato (Rodriguez and Redman 2008). Curvularia sp. confer thermo-tolerance to grasses and provided thermo-tolerance ability to other plants: tomato, watermelon, and wheat (Abo Nouh 2019).

Beauveria bassiana is an entomopathogenic fungus with worldwide distribution, which can live as a plant endophyte; colonization of plant tissues by $B$. bassiana has proved to protect against insect damage and inhibit insect establishment and development (Vega et al. 2008; Allegrucci et al.2017). B. bassiana was able to infect Tuta absoluta (leaf miner pest of tomato leaves) either by direct contact with conidia or indirectly by ingestion of tomato leaves colonized 
endophytically resulting in mortality up to $50 \%$ or higher (Allegrucci et al. 2017).

A study by Mahmoud and Narisawa (2013) reported that fungal endophyte, Scolecobasidium humicola, can enhance growth and biomass of tomato plant. Ampelomyces sp. and $P$. chrysogenum showed increased tomato drought and salt stress tolerance, respectively, and increased the overall fruit production after stress removal. Tomato plants colonized with Ampelomyces sp. isolated from plants growing in nutrient-poor soil under drought conditions were much healthier than NS plants under standard greenhouse conditions. Several studies have isolated Penicillium sp. from wild plants growing under salt stress and found them producing gibberellin and other bioactive compounds that promote growth, grain yield and shoot biomass of various plants (Khan et al. 2008). P. chrysogenum showed increased salt tolerance and showed significant increase in shoots growth compared to NS plants (Morsy et al. 2020).

\section{Conclusion}

This review concentrated on using fungal endophytes from the hosts thriving in high stress environments to confer desirable traits such as drought, temperature, disease and salt tolerance to genetically unrelated stress-sensitive plant species. Numerous studies indicate that fitness benefits conferred by mutualistic fungi contribute to or are responsible for plant adaptation to stress. Although other studies have shown that fungal endophytes confer stress tolerance to host species and play a significant role in the survival of at least some plants in high-stress environments. The interaction of plants with a rich endophytic consortium may influence plant gene expression and metabolism. Such intergenic epigenetic mechanisms would contribute to a successful plant response to abiotic and biotic stressors. There is an increasing interest in developing the potential biotechnological applications of fungal endophytes for improving plant stress tolerance and sustainable production of food crops. The ability of fungal endophytes to confer stress tolerance to plants may provide a novel strategy for mitigating the impacts of global climate change on agricultural and native plant communities.

\section{Acknowledgements}

This paper is based upon work supported by Science, Technology \& Innovation Funding Authority (STDF) under grant number 34837.

\section{Competing interests}

The authors declare that they have no competing interests.

\section{References}

Abo Nouh FA (2019) Endophytic fungi for sustainable agriculture. Microbial Bio system 4:31-44.

Abo Nouh FA and Abdel-Azeem AM (2020) Role of fungi in adaptation of agricultural crops to abiotic stresses. In: AN Yadav et al. (eds.), Agriculturally Important Fungi for Sustainable Agriculture, Fungal Biology, Springer Nature Switzerland AG 55-80.

Aimé S, Alabouvette C, Steinberg C, and Olivain C (2013) The endophytic strain Fusarium oxysporum Fo47: a good candidate for priming the defense responses in tomato roots. Mol Plant Microbe Interact 26: 918926.

Akello J and Sikora R (2012) Systemic acropedal influence of endophyte seed treatment on Acyrthosiphon pisum and Aphis fabae offspring development and reproductive fitness. Biol. Control, 61, 215-221.

Akutse KS, Maniania NK, Fiaboe KKM, Van den Berg J, Ekesi S (2013) Endophytic colonization of Vicia faba and Phaseolus vulgaris (Fabaceae) by fungal pathogens and their effects on the life-history parameters of Liriomyza huidobrensis (Diptera: Agromyzidae). Fungal Ecol. 6, 293-301.

Ali SkZ, Sandhya V, Rao LV (2014) Isolation and characterization of drought-tolerant ACC deaminase and exopolysaccharide-producing fluorescent Pseudomonas sp. Ann. Microbiol. 64, 493-502.

Allegrucci N, Velazquez MS, Russo ML, Perez E, Scorsetti AC (2017) Endophytic colonization of tomato by the entomopathogenic fungus Beauveria bassiana: the use of different inoculation techniques and their effects on the tomato leaf miner Tuta absoluta (Lepidoptera: Gelechiidae). J Plant Prot Res 57:205-211

Anjum S, Xie X, Wang L, Saleem M, Man C, Lei W (2011) Morphological, physiological and biochemical responses of plants to drought stress. J. Afr.Agric. Res. 6, 2026-2032.

Anupama N, Murali M, Jogaiah S, Amruthesh KN (2014) Crude oligosaccharides from Alternaria solani with Bacillus subtilis enhance defensive activity against early blight disease of tomato. Asian J. Sci. Tech. 5, 412-416.

Arnold AE (2007) Understanding the diversity of foliar endophytic fungi: progress, challenges, and frontiers. Fungal Biol Rev 21:51-66.

Arora J, Ramawat KG (2017) An introduction to endophytes. In: Maheshwari DK (ed) Endophytes: biology and biotechnology, sustainable development and biodiversity 15. Springer, Cham, pp 1-16. 
Azad K, Kaminskyj S (2016) A fungal endophyte strategy for mitigating the effect of salt and drought stress on plant growth. Symbiosis 68:73-78

Babu AN, Jogaiah S, Ito S, Amruthesh KN, Tran LSP (2015) Improvement of growth, fruit weight and early blight disease protection of tomato plants by rhizosphere bacteria is correlated with their beneficial traits and induced biosynthesis of antioxidant peroxidase and polyphenol oxidase. Plant Sci. 231, 62-73.

Bano A, Fatima M (2009) Salt tolerance in Zea mays (L.) following inoculation with Rhizobium and Pseudomonas. Biol. Fertility Soils 45, 405-413.

Batool N, Shahzad A, Ilyas N (2014) Plants and salt stress. Int J Agric Crop Sci 7:1439-14461.

Beutner S, Bloedorn B, Frixel S et al (2001) Quantitative assessment of antioxidant properties of natural colorants and phytochemicals: carotenoids, flavonoids, phenols and indigoids. The role of $\beta$ carotene in antioxidant functions. J Sci Food Agric 81:559-568.

Blaylock AD (1994) Soil salinity, salt tolerance and growth potential of horticultural and landscape plants. Cooperative Extension Service, University of Wyoming, Department of Plant, Soil and Insect Sciences, College of Agriculture, Laramie, Wyoming.

Bottner P, Couteaux MM, Vallejo VR (1995) Soil organic matter in Mediterranean-type ecosystems and global climatic changes: a case study-the soils of the Mediterranean basin. In: Jose, M., Oechel, W.C. (Eds.), Global Change and Mediterranean-type Ecosystems. Ecological studies, 117.SpringerVerlag, New York, pp. 306-325.

Boyer JS (1982) Plant productivity and environment. Science 218:443-448

Brundrett MC (2006) Understanding the roles of multifunctional mycorrhizal and endophytic fungi, In: B.J.E. Schulz, C.J.C. Boyle and T.N. Sieber (eds.) Microbial Root Endophytes. SpringerVerlag, Berlin, pp. 281-293.

Caravaca F, Alguacil MM, Herniandez JA, Roldain A (2005) Involvement of antioxidant enzyme and nitrate reductase activities during water stress and recovery of mycorrhizal Myrtus communis and Phillyrea angustifolia plants. Plant Sci. 169, 191197.

Carillo P, Annunziata MG, Pontecorvo G, Fuggi A, Woodrow P (2011) Salinity stress and salt tolerance. In: Shanker A (ed) Abiotic stress in plants mechanisms and adaptations. InTech, London, pp 21-38
Chadha N, Prasad R, Varma A (2015) Plant promoting activities of fungal endophytes associated with tomato roots from central Himalaya, India and their interaction with Piriformospora indica. Int J Pharm Bio Sci 6:333-343

Chaves MM, Maroco JP, Pereira JS et al (2003) Understanding plant responses to drought- from genes to the whole plant. Funct Plant Biol 30:239264

Chaw S, Chang C, Chen H, Li W (2004) Dating the monocot-dicot divergence and the origin of core eudicots using whole chloroplast genomes. J Mol Evol 58:424-441

Chhipa H, Deshmukh SK (2019) Fungal endophytes: rising tools in sustainable agriculture production. In: Jha $S$ (ed) Endophytes and secondary metabolites. Springer International Publishing AG, Cham, pp 124

Cohen AC, Bottini R, Pontin M, Berli FJ, Moreno D, Boccanlandro H, Piccoli PN (2015) Azospirillum brasilense ameliorates the response of Arabidopsis thaliana to drought mainly via enhancement of ABA levels. Physiol Plant 153:79-90

Cramer GR, Nowak RS (1992) Supplemental manganese improves the relative growth, net assimilation and photosynthetic rates of salt stressed barley. Physiol Plant 84(600):605

Cramer GR, Urano K, Delrot S, Pezzotti M, Shinozaki K (2011) Effects of abiotic stress on plants: a systems biology perspective. BMC Plant Biol 11:163

Cuartero J, Bolarín MC, Asíns MJ, Moreno V (2006) Increasing salt tolerance in the tomato. J Exp Bot 57:1045-1058

Dalezios NR, A Gobin, AMT Alfonso, S Eslamian (2017). Agricultural drought indices: Combining crop, climate, and soil factors, pp:73-89. In: Handbook of Drought and Water Scarcity, CRC Press

Daryanto S, L Wang, PA Jacinthe (2016). Global synthesis of drought effects on maize and wheat production. PLoS One 11; Article e0156362

Dastogeer KMG, Wylie SJ (2017) Plant-fungi association: role of fungal endophytes in improving plant tolerance to water stress. In: Singh DP et al (eds) Plant-microbe interactions in agro-ecological perspectives. Springer, Singapore, pp 143-160

Desneux N, Luna MG, Guillemaud T, Urbaneja A (2011) The invasive south american tomato pinworm, tuta absoluta, continues to spread in afro-eurasia and beyond: The new threat to tomato world production. Journal of Pest Science, 84, 403-408.

Faostat (2014) Crop production and area coverage.

Fusconi A, Berta G (2012) Environmental stress and role of arbuscular mycorrhizal symbiosis. In: Ahmad P, 
Prasad MNV (eds) Abiotic stress responses in plants. Springer, New York, pp 197-214

Glick BR, Cheng Z, Czarny J, Duan J (2007) Promotion of plant growth by ACC deaminase-producing soil bacteria. Eur. J. Plant Pathol. 119, 329-339

Graham JH and Eissenstat DM (1998) Field evidence for the carbon cost of citrus mycorrhizas. New Phytol. 140: 103-110.

Graham JH, Drouillard DL and Hodge NC (1996) Carbon economy of sour orange in response to different Glomus spp. Tree Physiol. 16: 1023-1029.

Grover M, Ali SKZ, Sandhya V, Rasul A, Venkateswarlu B (2011) Role of microorganisms in adaptation of agriculture crops to abiotic stresses. World J Microbiol Biotechnol 27:1231-1240

Hallman J, Sikora R (1995) Influence of Fusarium oxysporum, a mutualistic fungal endophyte, on Meloidogyne incognita infection of tomato. Plant Dis Protect 101: 475-481.

Hassan ES (2017) Plant growth-promoting activities for bacterial and fungal endophytes isolated from medicinal plant of Teucrium polium L. J. Adv. Res. $8,687-695$

Hendry GA (2005) Oxygen free radical process and seed longevity. Seed Sci. J. 3,141-147

Higa $T$ (2004) Effective microorganisms - a new dimension for nature farming. In: Parr JF, Hornick SB, Simpson ME (eds) Proceedings of the second international nature farming conference on U.S. Department of Agriculture, Washington, DC, USA, pp 20-22

Hsiao A (2000) Effect of water deficit on morphological and physiological characterizes in Rice (Oryza sativa). J. Agric. 3, 93-97.

Hussain SS, Mehnaz S, KHM S (2018) Harnessing the plant microbiome for improved abiotic stress tolerance. In: Egamberdieva D, Ahmad P (eds) Plant microbiome: stress response, microorganisms for sustainability, vol 5. Springer, Singapore, pp 2143

Hyakumachi M (1994) Plant-growth-promoting fungi from turfgrass rhizosphere with potential for disease suppression. Soil Microorgan 44:53-68

Hyde KD, Soytong K (2008) The fungal endophyte dilemma. Fungal Divers., 33, 163-173

Jaleel CA, Manivannan P, Wahid A, Farooq M, Al-Juburi HJ, Somasundaram R, Vam RP (2009) Drought stress in plants: a review on morphological characteristics and pigments composition. Int. J. Agric. Biol. 11, 100-105.

Jamil A, Riaz S, Ashraf M, Foolad MR (2011) Gene expression profiling of plants under salt stress. Crit Rev Plant Sci 30: 435-458
Jia Q, Qu J, Mu H, Sun H, Wu C (2020) Foliar endophytic fungi: Diversity in species and functions in forest ecosystems. Symbiosis, 80, 102-132.

Jogaiah S, Abdelrahman M, Tran L-SP, Ito S-I (2018) Different mechanisms of Trichoderma virensmediated resistance in tomato against Fusarium wilt involve the jasmonic and salicylic acid pathways. Mol. Plant Pathol. 19, 870-882.

Jogaiah S, Abdelrahman M, Tran LSP, Shin-ichi I (2013) Characterization of rhizosphere fungi that mediate resistance in tomato against bacterial wilt disease. $\mathbf{J}$ Exp Bot 64:3829-3842

Kasim WA, Osman ME, Omar MN, Abd El-Daim IA, Bejai S, Meijer J (2013) Control of drought stress in wheat using plant growth promoting bacteria. J.Plant Growth Regul. 32, 122-130.

Kaur T, Rana KL, Kour D, Sheikh I, Yadav N, Yadav AN, Dhaliwal HS, Saxena AK (2020) Microbe-mediated biofortification for micronutrients: present status and future challenges. In: Rastegari AA, Yadav AN, Awasthi AK, Yadav N (eds) Trends of microbial biotechnology for sustainable agriculture and biomedicine systems: perspectives for human health. Elsevier, Amsterdam, pp 1-17.

Khan SA, Hamayun M, Khan AL, Shinwari ZK (2012) Isolation of plant growth promoting endophytic fungi from dicots inhabiting coastal sand dunes of Korea. Pak J Bot 44:1453-1460

Khan AL, Waqas M, Hussain J, Al-Harrasi A, Hamayun M, Lee IJ (2015) Phytohormones enabled endophytic fungal symbiosis improve aluminum phytoextraction in tolerant Solanum lycopersicum: An example of Penicillium janthinellum LK5 and comparison with exogenous GA3. J. Hazard. Mater. 295, 70-78.

Khan AL, Waqas M, Kang SM, Al-Harrasi A, Hussain J, Al-Rawahi A, Al-Khiziri S, Ullah I, Ali L, Jung HY, Lee IJ (2014) Bacterial endophyte Sphingomonas sp. LK11 produces gibberellins and IAA and promotes tomato plant growth. J. Microbiol. 52, 689-695.

Khan SA, Hamayun M, Yoon H, Kim H-Y, Suh S-J, Hwang P, Kim J-M, Lee S-U, Choo Y-S, Yoon U$\mathrm{H}$ et al. (2008) Plant growth promotion and Penicillium citrinum. BMC Microbiol. 8, 231.

Khan AL, Waqas M, Khan AR, Hussain J, Kang SM, Gilani SA, Hamayun M, Shin JH, Kamran M, AlHarrasi A, et al. (2013) Fungal endophyte Penicillium janthinellum LK5 improves growth of ABA-deficient tomato under salinity. World J. Microbiol. Biotechnol. 29, 2133-2144.

Khare E, Mishra J, Arora NK (2018) Multifaceted interactions between endophytes and plant: 
developments and prospects. Front Microbiol 9:112

Khalmuratova I, Kim H, Nam YJ (2015) Diversity and plant growth promoting capacity of endophytic fungi associated with halophytic plants from the west coast of Korea. Mycobiology 43:373-383

Khiralla A, Spina R, Yagi S, Mohamed L, Laurain-Mattar D (2016) Endophytic fungi: occurrence, classification, function and natural products. In: Hughes E (ed) Endophytic fungi: diversity, characterization and biocontrol. Nova Science, New York, pp 1-19

Kour D, Rana KL, Yadav N, Yadav AN, Kumar A, Meena VS, Singh B, Chauhan VS, Dhaliwal HS, Saxena AK (2019) Rhizospheric microbiomes: biodiversity, mechanisms of plant growth promotion, and biotechnological applications for sustainable agriculture. In: Kumar A, Meena VS (eds) Plant growth promoting rhizobacteria for agricultural sustainability: from theory to practices. Springer, Singapore, pp 19-65. https://doi.org/10.1007/978-981-13-7553-8_2

Kusari S, Spiteller M (2012) Metabolomics of endophytic fungi producing associated plant secondary metabolites: progress, challenges and opportunities. In: Roessner U (ed) Metabolomics. InTech, Rijeka, pp 241-266

Limtong S, Koowadjanakul N (2012) Yeasts from phylloplane and their capability to produce indole3-acetic acid. World J Microbiol Biotechnol 28:3323-3335

Lata R, Chowdhury S, Gond S, White JF (2018) Induction of abiotic stress tolerance in plants by endophytic microbes. Appl Microbiol 66:268-276

Latef AAHA, Hashem A, Rasool S, Abd-Allah EF, Alqarawi AA, Egamberdieva D, Jan S, Anjum NA, Ahmad P (2016) Arbuscular mycorrhizal symbiosis and abiotic stress in plants: a review. J Plant Biol 59:407

Lewis GC, Clements RO (1986) A survey of ryegrass endophyte (Acremonium lolii) in the U.K. and its apparent ineffectuality on a seedling pest. J Agric Sci 107:633-638

Lin L, Xu X (2013) Indole-3-acetic acid production by endophytic Streptomyces sp. En-1 isolated from medicinal plants. Curr. Microbiol. 67, 209-217.

Liu Y, Y Hwang (2015). Improving drought predictability in Arkansas using the ensemble PDSI forecast technique. Stochastic Environ Res Risk Assessm 29:79-91

López-Ráez JA (2016) How drought and salinity affect arbuscular mycorrhizal symbiosis and strigolactone biosynthesis? Planta 243:1375-1385
Lugtenberg BJJ, Caradus JR, Johnson LJ (2016) Fungal endophytes for sustainable crop production. FEMS Microb Ecol 92:1-17

Mahajan S, Tuteja N (2005) Cold, salinity and drought stresses: an overview. Arch Biochem Biophys 444:139-158

Mahmoud RS, Narisawa K (2013) A new fungal endophyte, Scolecobasidium humicola, promotes tomato growth under organic nitrogen conditions. PLoS One 8:e78746

Maggio A, Hasegawa PM, Bressan RA, Consiglio MF, Joly RJ (2001) Unravelling the functional relationship between root anatomy and stress tolerance. Funct Plant Biol 28:999-1004

Mannocchi F, F Todisco, L Vergni (2004). Agricultural drought: Indices, definition and analysis. In: The Basis of Civilization-Water Science. Proceedings of die UNESCO/IAHS/IWIIA Symposium held in Rome. December 2003. IAHS Publication, Vol. 286, p:246, Wallingford, UK

Matsuoka H, Akiyama M, Kobayashi K, Yamaji K (2013) $\mathrm{Fe}$ and $\mathrm{P}$ solubilization under limiting conditions by bacteria isolated from Carex kobomugi roots at the Hasaki Coast. Curr. Microbiol. 66, 314-321.

Meena H, Ahmed MA, Prakash P (2015) Amelioration of heat stress in wheat, Triticum aestivum by PGPR (Pseudomonas aeruginosa strain 2CpS1). Biosci Biotech Res Comm 8:171-17

Meng Q, X Chen, DB Lobell, Z Cui, Y Zhang, H Yang, F Zhang (2016) Growing sensitivity of maize to water scarcity under climate change. Sci Rep 6; Article 19605

Morsy M, Cleckler B and Armuelles-Millican H (2020) Fungal endophytes promote tomato growth and enhance drought and salt tolerance. Plants 9, 877; doi:10.3390/plants9070877

Munns R (2002) Comparative physiology of salt and water stress. Plant Cell Environ 25:239-250

Munns R (2005) Genes and salt tolerance: bringing them together. New Phytol. 167, 645-663.

Munns R, Tester M (2008) Mechanisms of salinity tolerance. Annu Rev Plant Biol 59:651-681

Murali M, Sudisha J, Amruthesh KN, Ito S-I, Shetty HS (2013) Rhizosphere fungus Penicillium chrysogenum promotes growth and induces defence-related genes and downy mildew disease resistance in pearl millet. Plant Biol. 15, 111-118.

Mushtaq S, Nasim G, Khokhar I, Mukhtar I (2012) Effects of Penicillium extracts on germination vigour in subsequent seedling growth of tomato (Lycopersicon esculentum L.). Arch. Phytopathol. Plant Protect. 45, 932-937. 
Naveed M, Hussain MB, Zahir ZA, Mitter B, Sessitsch A (2014) Drought stress amelioration in wheat through inoculation with Burkholderia phytofirmans strain PsJN. Plant Growth Regul 73:121-131

Nefzi A, Jabnoun-Khiareddine H, Aydi Ben Abdallah R, Ammar N, Medimagh-Saïdana S, et al. (2017) Suppressing Fusarium Crown and Root Rot infections and enhancing the growth of tomato plants by Lycium arabicum Schweinf. Ex Boiss. extracts. S Afr J Bot 113: 288-299.

Nefzi A, Abdallah RAB, Jabnoun-Khiareddine H, Ammar N, Daami-Remadi M (2019) Ability of endophytic fungi associated with Withania somnifera L. to control Fusarium Crown and Root Rot and to promote growth in tomato. Braz. J. Microbiol. 50, 481-494.

Niu K, Guo H, Kakizaki M, Cui Y, Ohmori-Matsuda K, Guan L, Hozawa A, Kuriyama S, Tsuboya, T, Ohrui T, Furukawa K, Arai H, Tsuji I, Nagatomi R (2013) A tomato rich diet is related to depressive symptoms among an elderly population aged 70 years and over: a population-based, cross-sectional analysis. J. Affect. Disord. 144, 165-170.

Parker L, C Bourgoin, A Martinez-Valle, P Läderach (2019). Vulnerability of the agricultural sector to climate change: The development of a pan-tropical climate risk vulnerability assessment to inform subnational decision making. PLoS One 14; Article $\mathrm{e} 0213641$

Parthasarathy, R.; Chandrika, M.; Rao, H.C.; Kamalraj, S.; Jayabaskaran, C.; Pugazhendhi, A. Molecular profiling of marine endophytic fungi from green algae: Assessment of antibacterial and anticancer activities. Process. Biochem. 2020, 96, 11-20.

Pieterse CMJ, Dicke M (2007) Plant interactions with microbes and insects: from molecular mechanisms to ecology. Trends Plant Sci 12:564-569

Valli PS, Muthukumar T (2018) Dark septate root Endophytic fungus Nectria haematococca improves tomato growth under water limiting conditions. Indian J. Microbiol. 58, 489-495.

Qian D, Zhao Y, Yang D (2017) Systematic review of chemical constituents in the genus Lycium (Solanaceae). Molecules 22: 911-936.

Rahdari P, Hoseini SM (2012) Drought stress, a review. Int. J. Agron. Plant Prod. 3,443-446.

Rahdari P, Hoseini SM, Tavakoli S (2012) The studying effect of drought stress on germination, proline, sugar, lipid, protein and chlorophyll content in Purslane (Portulaca oleraceae L.) leaves. J. Med. Plants Res. 6, 1539-1547.
Raghuwanshi R (2018) Fungal community in mitigating impacts of drought in plants. In: Gehlot P, Singh J (eds) Fungi and their role in sustainable development: current perspectives. Springer, Singapore, pp 267-382

Rana KL, Kour D, Sheikh I, Yadav N, Yadav AN, Kumar V, Singh BP, Dhaliwal HS, Saxena AK (2019) Biodiversity of endophytic fungi from diverse niches and their biotechnological applications. In: Singh BP (ed) Advances in endophytic fungal research: present status and future challenges. Springer, Cham, pp 105-144.

Rana KL, Kour D, Kaur T, Sheikh I, Yadav AN, Kumar V, Suman A, Dhaliwal HS (2020) Endophytic microbes from diverse wheat genotypes and their potential biotechnological applications in plant growth promotion and nutrient uptake. Biological Sciences 90(1):1-11

Redman RS, Ranson J, Rodriguez RJ (1999) Conversion of the pathogenic fungus Colletotrichum magna to a nonpathogenic endophytic mutualist by gene disruption. Mol Plant-Microbe Interact 12:969-975

Redman RS, Dunigan DD, Rodriguez RJ (2001) Fungal symbiosis: from mutualism to parasitism, who controls the outcome, host or invader? New Phytol 151:705-716

Redman RS, Sheehan KB, Stout RG, Rodriguez RJ, Henson JM (2002) Thermotolerance conferred to plant host and fungal endophyte during mutualistic symbiosis. Science 298:1581

Redman RS, Kim YO, Woodward CJDA, Greer C, Espino L, Doty SL, Rodriguez RJ (2011) Increased fitness of rice plants to abiotic stress via habitat adapted symbiosis: a strategy for mitigating impacts of climate change. PLoS ONE 6:1-10

Rodriguez R, Redman R (2008) More than 400 million years of evolution and some plants still can't make it on their own: plant stress tolerance via fungal symbiosis. J Exp Bot 59:1109-1114

Rodriguez MA, Cabrera G, Godeas A (2006) Cyclosporine A from a nonpathogenic Fusarium oxysporum suppressing Sclerotinia sclerotiorum. J Appl Microbiol 100: 575-586.

Rodriguez RJ, Henson J, Van Volkenburgh E, Hoy M (2008) Stress tolerance in plants via habitat-adapted symbiosis. Int Soc Microb Ecol J 2:404-416

Rodriguez RJ, White JF, Arnold AE, Redman RS et al (2009) Fungal endophytes: diversity and functional roles. New Phytol 182:314-330

Saad MMG and Badry HH (2020) Phytohormones producing fungal endophytes enhance nutritional status and suppress pathogenic fungal infection in 
tomato J. Agr. Sci. Tech. Vol. 22(5): 1383-1395 1383

Sánchez-Rodríguez AR, Raya-Díaz S, Zamarreño ÁM, García-Mina JM, Del Campillo MC, QuesadaMoraga E (2018) An endophytic Beauveria bassiana strain increases spike production in bread and durum wheat plants and effectively controls cotton leafworm (Spodoptera littoralis) larvae. Biol. Control. 116, 90-102.

Savvas D (2003) Hydroponics: A modern technology supporting the application of integrated crop management in greenhouse. J Food Agric Environ $1: 80-86$

Saxena AK, Yadav AN, Rajawat M, Kaushik R, Kumar R, Kumar M, Prasanna R, Shukla L (2016) Microbial diversity of extreme regions: an unseen heritage and wealth. Indian J Plant Genet Resour 29:246-248

Selvakumar G, Panneerselvam P, Ganeshamurthy AN (2012) Bacterial mediated alleviation of abiotic stress in crops. In: Maheshwari, D.K. (Ed.), Bacteria in agrobiology: Stress management. SpringerVerlag, Berlin Heidelberg, pp.205-224.

Schulz BJE (2006) Mutualistic interactions with fungal root endophytes. In: Schulz BJE, Boyle CJC, Sieber TN (eds) Microbial root endophytes. Springer, Berlin, pp 261-280

Schulz B, Boyle C (2005) The endophytic continuum. Mycol Res 109:661-686

Schulz B, Boyle C, Draeger S, Römmert AK, Krohn K (2002) Endophytic fungi: a source of novel biologically active secondary metabolites. Mycol Res 106: 996-1004.

Schardl C and Leuchtmann A (2005) The Epichloe endophytes of grasses and the symbiotic continuum, In: J. Dighton, J.F. White and P. Oudemans (eds.) The Fungal Community: Its organization and role in the ecosystem. Taylor \& Francis, Boca Raton, FL, pp. 475-503.

Schwarz D, Schröder FG and Kuchenbuch R (1996) Efficiency of tomato roots for water and nutrient uptake from two closed hydroponic systems. International Society for Soilless Culture. 61: 249255.

Shahbaz M, Ashraf M (2013) Improving salinity tolerance in cereals. Crit. Rev. Plant Sci. 32, 237-249.

Singh LP, Gill SS, Tuteja N (2011) Unraveling the role of fungal symbionts in plant abiotic stress tolerance. Plant Signal Behav 6:175-191

Singh A, Kumari R, Yadav AN, Mishra S, Sachan A, Sachan SG (2020) Tiny microbes, big yields: microorganisms for enhancing food crop production sustainable development. In: Rastegari AA, Yadav AN, Awasthi AK, Yadav N (eds)
Trends of microbial biotechnology for sustainable agriculture and biomedicine systems: diversity and functional perspectives. Elsevier, Amsterdam, pp $1-16$.

Skirycz A, Inze D (2010) More from less: plant growth under limited water. Curr Opin Biotechnol 21:197203

Smirnoff N (1993) The role of Reactive Oxygen in the response of plants to water deficit and desiccation. J. New Phytol. 125, 27-30.

Srivastava R, Mehta CM, Sharma AK (2011) Fusarium pallidoroseum - a new biofertilizer responsible for enhancing plant growth in different crops. Int Res J Microbiol 2:192-199

Talaat NB (2014) Effective microorganisms enhance the scavenging capacity of the ascorbate-glutathione cycle in common bean (Phaseolus vulgaris L.) plants grown in salty soils. Plant Physiol Biochem 80:136-143

Talaat NB (2015) Effective microorganisms improve growth performance and modulate the ROSscavenging system in common bean (Phaseolus vulgaris $\mathrm{L}$.) plants exposed to salinity stress. J Plant Growth Regul 34:35-46

Talaat NB, Shawky BT (2013) Modulation of nutrient acquisition and polyamine pool in salt-stressed wheat (Triticum aestivum L.) plants inoculated with arbuscular mycorrhizal fungi. Acta Physiol Plant 35:2601-2610

Tucci M, Ruocco M, De Masi L, De Palma M, Lorito M (2011) The beneficial effect of Trichoderma spp. on tomato is modulated by the plant genotype. Mol. Plant. Pathol. 12, 341-354.

Vega FE, Posada F, Aime MC, Pavaripoll M, Infante F, Rehner SA (2008) Entomopathogenic fungal endophytes. Biol Control 46:72-82

Vergara C, Araujo KEC, Urquiaga S, Schultz N, de Balieiro FC, Medeiros PS, Santos LA, Xavier GR, Zilli JE (2017) Dark Septate endophytic fungi help tomato to acquire nutrients from ground plant material. Front. Microbiol. 8, 1-12.

Verma S, Nizam S, Verma PK (2013) Biotic and abiotic stress signaling in plants. Stress Signal Plants 1:2549

Venkateswarlu B, Shanker AK (2009) Climate change and agriculture: adaptation and mitigation strategies. Indian J. Agron. 54, 226-230.

Wang Y, Frei M (2011) Stressed food-the impact of abiotic environmental stresses on crop quality. Agric Ecosyst Environ 141:271-286

Wang WX, Vinocur B, Shoseyov O, Altman A (2001) Biotechnology of plant osmotic stress tolerance: 
physiological and molecular considerations. Acta Hortic 560:285-292

Yadav AN, Kumar R, Kumar S, Kumar V, Sugitha T, Singh B, Chauhan V, Dhaliwal HS, Saxena AK (2017) Beneficial microbiomes: biodiversity and potential biotechnological applications for sustainable agriculture and human health. J Appl Biol Biotechnol 5:45-57

Yadav AN (2017) Agriculturally important microbiomes: biodiversity and multifarious PGP attributes for amelioration of diverse abiotic stresses in crops for sustainable agriculture. Biomed J Sci Tech Res 1:14

Yadav AN (2019) Endophytic fungi for plant growth promotion and adaptation under abiotic stress conditions. Acta Sci Agric 3:91-93

Yadav AN, Yadav N (2018) Stress-adaptive microbes for plant growth promotion and alleviation of drought stress in plants. Acta Sci Agric 2:85-88

Yakti W, Kovács GM, Vági P, Franken P (2018) Impact of dark septate endophytes on tomato growth and nutrient uptake. Plant. Ecol. Divers. 11, 637-648.

Yang YW, Lai KN, Tai PY and Li WH (1999) Rates of nucleotide substitution in angiosperm mitochondrial DNA sequences and dates of divergence between Brassica and other angiosperm lineages. J. Mol. Evol. 48: 597-604.

Young CA Hume DE McCulley RL (2013) Forages and Pastures Symposium: Fungal endophytes of tall fescue and perennial ryegrass: Pasture friend or foe? J. Anim. Sci. 91, 2379-2394.

Yue B, Xue W, Xiong L, Yu X, Luo L, Cui K, Jin D et al (2006) Genetic basis of drought resistance at reproductive stage in rice: separation of drought tolerance from drought avoidance. Genetics 172:1213-1228.

Zabalgogeazcoa I (2008) Fungal endophytes and their interaction with plant pathogens. Spanish J Agri Res 6:138-146.

Zahir ZA, Munir A, Asghar HN, Arshad M, Shaharoona B (2008) Effectiveness of rhizobacteria containing ACC-deaminase for growth promotion of peas (Pisum sativum) under drought conditions. J. Microbiol. Biotechnol. 18 (5), 958-963.

Zavala-Gonzalez EA, Escudero N, Lopez-Moya F, Aranda-Martinez A, Exposito A, Ricaño-Rodríguez J, Naranjo-Ortiz MA, Ramírez-Lepe M, LopezLlorca LV (2015) Some isolates of the nematophagous fungus Pochonia chlamydosporia promote root growth and reduce flowering time of tomato. Ann. Appl. Biol. 166, 472-483.

Zhu JK (2007) Salt tolerance and salinity effects on plants: a review. Ecotoxicol Environ Saf 60:324-349. 